\title{
EFEKTIFITAS TEKNIK COUNTER PRESSURE DAN ABDOMINAL LIFTING TERHADAP PENGURANGAN RASA NYERI PADA IBU BERSALIN KALA I FASE AKTIF DI BPM KOTA PADANG
}

\section{THE EFFECTIVENESS OF COUNTER PRESSURE AND ABDOMINAL LIFTING TECHNIQUES ON PAIN REDUCTION IN FIRST STAGE ACTIVE MATERNAL MOTHERS IN BPM PADANG CITY}

\author{
Mahdalena Prihatin Ningsih, Lisa Rahmawati* \\ *Prodi D III Kebidanan Padang Poltekkes Kemenkes Padang \\ Korespondensi: lisarahmawati2406@gmail.com
}

\begin{abstract}
Labor pain is a physiological condition that will generally be experienced by almost all mothers who will give birth. Labor pain can be reduced if done with counter pressure and abdominal lifting techniques, namely by pressing the sacrum bone and abdominal massage. This technique is one of the reductions in pain of non-pharmacological labor done to the mother in the first phase of the active phase of labor. This study aims to determine the effectiveness of abdominal lifting techniques and counter pressure techniques to reduce labor pain. This type of research is a quasi-experimental one group pretest and post-test. The population in this study were all firstphase first-time mothers in the Independent Practice Midwife of the City of Padang. The method of collecting samples by purposive sampling with a total sample of 16 people. Data collection uses a scale of pain intensity at the time of the pretest before the intervention and post-test after the intervention. Univariate and bivariate data processing. Univariate research results found that the average labor pain before abdominal lifting technique was 7.63 with a standard deviation of 1.23 and a counter-pressure technique of 7.81 with a standard deviation of 1.33 , while the results of univariate research after abdominal lifting technique was 7.19 with a standard deviation of 1.47 and a counter-pressure technique of 6.56 with a standard deviation of 1.41. The results of the bivariate study found that there was the effectiveness of counterpressure techniques to reduce the pain score of the first phase active labor with a p-value of 0,000 and there was no effective abdominal lifting technique for the reduction of the first phase active labor pain with a p-value of 0.110. It is expected that respondents and health workers can apply counter pressure and abdominal lifting techniques in labor to help reduce the pain felt during labor to increase maternal comfort.
\end{abstract}

Keywords $\quad$ : Counter Pressure, Abdominal Lifting, Labor Pain

\begin{abstract}
ABSTRAK
Nyeri persalinan merupakan kondisi fisiologis yang secara umum akan dialami oleh hampir semua ibu yang akan melahirkan. Rasa nyeri persalinan dapat berkurang bila dilakukan dengan teknik counter pressure dan abdominal lifting yakni dengan menekan tulang sakrum dan massage abdominal. Teknik ini merupakan salah satu pengurangan rasa nyeri persalinan non farmakologi yang dilakukan pada ibu dalam kala I fase aktif persalinan. Penelitian ini bertujuan untuk mengetahui Efektifitas teknik abdominal lifting dan teknik counter pressure terhadap pengurangan rasa nyeri persalinan. Jenis penelitian ini adalah kuasi eksperimen dengan one
\end{abstract}


group pretest dan post test. Populasi dalam penelitian ini yaitu seluruh ibu bersalin kala I fase aktif di Bidan Praktik Mandiri Kota Padang. Metoda pengumpulan sampel secara purposive sampling dengan jumlah sampel sebanyak 16 orang. Pengumpulan data menggunakan skala intensitas nyeri pada saat pretest sebelum dilakukan intervensi dan post test setelah dilakukan intervensi. Pengolahan data secara univariat dan bivariat. Hasil penelitian univariat didapatkan bahwa rata-rata nyeri persalinan sebelum teknik abdominal lifting 7,63 dengan standar deviasi 1,23 dan teknik counter pressure 7,81 dengan standar deviasi 1,33, sedangkan hasil penelitian univariat sesudah dilakukan teknik abdominal lifting sebesar 7,19 dengan standar deviasi 1,47 dan teknik counter pressure sebesar 6,56 dengan standar deviasi 1,41. Hasil penelitian bivariat didapatkan bahwa terdapat efektifitas teknik counter pressure terhadap pengurangan skor nyeri persalinan kala I fase aktif dengan nilai p 0,000 dan tidak terdapat efektifitas teknik abdominal lifting terhadap pengurangan nyeri persalinan kala I fase aktif dengan nilai p 0,110. Diharapkan responden dan tenaga kesehatan dapat mengaplikasikan teknik counter pressure dan abdominal lifting dalam persalinan agar dapat membantu mengurangi nyeri yang dirasakan selama persalinan sehingga dapat meningkatkan kenyamanan ibu.

\section{Kata Kunci: Counter Pressure, Abdominal Lifting, Nyeri Persalinan}

\section{PENDAHULUAN}

Nyeri saat persalinan merupakan kondisi fisiologis yang secara umum dialami oleh hampir semua ibu yang akan bersalin. Nyeri persalinan merupakan sebuah pengalaman subjektif dari pasien yang disebabkan oleh iskemik otot uterus, penarikan dan traksi dari ligament uterus, traksi ovarium, tuba fallopii dan distensi bagian bawah uterus, otot dasar panggul dan perineum. Nyeri persalinan mulai timbul pada kala I fase laten dan akan lebih meningkat lagi intensitas nyeri tersebut pada fase aktif, pada fase laten terjadi pembukaan serviks sampai $3 \mathrm{~cm}$ bisa berlangsung selama 8 jam.

Rasa nyeri pada persalinan muncul akibat respons psikis dan refleks fisik sehingga ibu tidak merasa mampu akan bisa melewati nyeri tersebut dengan baik, banyak diantara ibu merasa cepat putus asa dan tidak kuat menahan rasa sakit. Nyeri akan berdampak pada peningkatan aktivitas sistem saraf simpatik yang dapat mengakibatkan perubahan tekanan darah, denyut nadi, pernafasaan, dan warna kulit, mual muntah, dan juga keringat berlebihan. Perubahan tingkah laku tertentu akibat nyeri juga sering terlihat seperti peningkatan rasa cemas dengan pemikiran yang menyempit, mengerang, menangis, gerakan tangan dan ketegangan otot yang sangat di seluruh tubuh. Ketegangan emosi akibat rasa cemas dan rasa takut dapat memperberat persepsi ibu terhadap nyeri selama persalinan. Nyeri persalinan akan menimbulkan ketakutan sehingga muncul kecemasan yang berakhir dengan kepanikan. Stres merupakan salah satu penyebab terjadinya partus lama. Sedangkan pemicu terjadinya stres dalam 
persalinan adalah timbulnya rasa nyeri selama persalinan.

Menurut sebuah penelitian kecemasan dan rasa takut merupakan gejala yang berhubungan dengan pengalaman nyeri terutama pada wanita. Hasil penelitian didapatkan bahwa responden yang mengalami nyeri menunjukkan terdapat hubungan positif antara sensitivitas kecemasan dan nyeri. Penelitian ini menunjukkan bahwa semakin tinggi tingkat kecemasan yang dialami seseorang maka akan dapat memperburuk kondisi nyeri yang dialami.

Masase merupakan salah satu teknik aplikasi teori gate-control, dengan menggunakan teknik masase atau pijat dapat meredakan nyeri dengan menghambat sinyal nyeri, meningkatkan aliran darah dan oksigenasi ke seluruh jaringan. Berdasarkan penelitian Pratiwi (2013) terdapat perbedaan yg signifikan dalam penurunan rasa nyeri pada teknik Counter presure dibandingkan teknik abdominal lifting.

Berdasarkan studi pendahuluan yang peneliti lakukan di Wilayah Kota Padang didapatkan ibu merasa nyeri yang berlebihan saat menghadapi persalinan sehingga ibu meminta untuk di operasi/dilakukan Sectio Caesarea (SC) dari pada melahirkan normal karena ibu merasa tidak kuat merasakan rasa nyeri terutama pada fase aktif kala 1 tersebut. Mengingat begitu pentingnya teknik counter pressure dan abdominal lifting, maka peneliti tertatrik untuk melakukan penelitian dengan judul "efektifitas teknik Counter Pressure dengan teknik Abdominal Lifting dalam mengatasi rasa nyeri pada ibu bersalin kala I fase aktif di BPM Kota Padang”.

\section{METODE}

Jenis penelitian yang digunakan yaitu kuasi eksperimen dengan one group pretest dan posttest design. Populasi pada penelitian ini adalah seluruh ibu bersalin kala I fase aktif di Bidan Praktik Mandiri Kota Padang, yaitu sebanyak 16 orang. Teknik pengambilan sampel menggunakan teknik purposive sampling. Data dikumpulkan menggunakan skala intensitas nyeri pada saat pretest sebelum dilakukan intervensi dan post test setelah dilakukan intervensi. Pengolahan data secara univariat dan bivariat menggunakan $t$-test dependen.

\section{HASIL DAN PEMBAHASAN}

\section{Analisis Univariat}

Tabel 1 Rata-Rata Skor Nyeri Persalinan Kala I Fase Aktif Sebelum Dilakukan Teknik Counter Pressure dan Abdominal Lifting

\begin{tabular}{cccccc}
\hline & N & Mean & SD & Min & Max \\
\hline $\begin{array}{c}\text { Teknik } \\
\text { Counter }\end{array}$ & 16 & 7.81 & 1.33 & 7.12 & 8.37 \\
$\begin{array}{c}\text { Pressure } \\
\text { Teknik } \\
\begin{array}{c}\text { Abdominal } \\
\text { Lifting }\end{array}\end{array}$ & 16 & 7.63 & 1.23 & 7.00 & 8.18 \\
\hline
\end{tabular}


Berdasarkan tabel 1 diketahui bahwa dari 16 orang responden didapatkan ratarata skor nyeri persalinan kala I fase aktif sebelum dilakukan teknik counter pressure yaitu 7,81, standar devisiasi 1,33, sedangkan rata-rata skor nyeri persalinan kala I fase aktif sebelum diberikan tekni Abdominal Lifting yaitu 7,63, dengan standar deviasiasi 1,23 .

Tabel 2 Rata-Rata Skor Nyeri Persalinan Kala I Fase Aktif Setelah Dilakukan Teknik Counter Pressure dan Abdominal Lifting

\begin{tabular}{cccccc}
\hline & n & Mean & SD & Min & Max \\
\hline $\begin{array}{c}\text { Teknik } \\
\text { Counter } \\
\text { Pressure }\end{array}$ & 16 & 6.56 & 1.41 & 5.81 & 7.18 \\
\hline $\begin{array}{c}\text { Teknik } \\
\text { Abdominal } \\
\text { Lifting }\end{array}$ & 16 & 7.19 & 1.47 & 6.50 & 7.93 \\
\hline & Berdasarkan tabel 2 diketahui bahwa
\end{tabular}

dari 16 orang responden didapatkan ratarata skor nyeri persalinan kala I fase aktif setelah dilakukan teknik counter pressure yaitu 6,56, standar devisiasi 1,41, sedangkan rata-rata skor nyeri persalinan kala I fase aktif setelah diberikan teknik abdominal lifting yaitu 7,19, dengan standar deviasiasi 1,47 .

\section{Analisis Bivariat}

Tabel 3 Efektifitas Teknik Counter Pressure Terhadap Skor Nyeri Persalinan Kala I Fase Aktif

\begin{tabular}{lcccccc}
\hline \multicolumn{1}{c}{$\begin{array}{c}\text { Skor } \\
\text { Nyeri }\end{array}$} & n & Mean & SD & Min & Max & p Value \\
\hline $\begin{array}{l}\text { Sebelum } \\
\text { dan }\end{array}$ & & & & & & \\
$\begin{array}{l}\text { Sesudah } \\
\text { Teknik } \\
\begin{array}{l}\text { Counter } \\
\text { Pressure }\end{array}\end{array}$ & 16 & 1,25 & 0,58 & 0,94 & 1,56 & 0,000 \\
\hline
\end{tabular}

Berdasarkan tabel 3, dari 16 orang responden didapatkan perbedaan rata-rata skor nyeri persalinan kala I fase aktif sebelum dan setelah dilakukan teknik counter pressure yaitu 1,25 dengan standar devisiasi 0,58. Hasil uji statistik dengan menggunakan paired sample t-test didapatkan nilai p value 0,000 , artinya Ho ditolak dan terdapat perbedaan skor nyeri persalinan kala I fase aktif sebelum dan setelah diberikan teknik counter pressure pada ibu bersalin di BPM Kota Padang.

\begin{tabular}{ccc}
\multicolumn{2}{c}{ Berdasarkan hasil tersebut } \\
menunjukkan masase counter pressure
\end{tabular} merupakan teknik masase yang memiliki kontribusi besar dalam menurunkan nyeri persalinan kala I fase aktif. Hal ini dapat terjadi dengan beberapa kemungkinan diantaranya adalah kebenaran teori gate control yang mengatakan bahwa selama proses persalinan impuls nyeri berjalan dari uterus sepanjang serat-serat saraf besar kearah uterus ke substansia gelatinosa di dalam spinal kolumna, sel-sel transmisi memproyeksikan pesan nyeri ke otak. Adanya stimulasi (seperti vibrasi, menggosok-gosok atau masase) mengakibatkan pesan yang berlawanan yang lebih kuat, cepat dan berjalan sepanjang serat saraf kecil. Pesan yang berlawanan ini menutup subtansi gelatinosa lalu memblokir pesan nyeri sehingga otak tidak mencatat pesan nyeri tersebut. 
Teknik counter pressure dilakukan di daerah lumbal dimana saraf sensorik rahim dan mulut rahim berjalan bersama saraf simpatis rahim memasuki sumsum tulang belakang melalui saraf torakal 10-11-12 sampai lumbal 1. Dengan begitu impuls rasa sakit ini dapat diblok yaitu dengan memberikan rangsangan pada saraf yang berdiameter besar yang menyebabkan gate control akan tertutup dan rangsangan sakit tidak dapat diteruskan ke korteks serebral. Teknik counter pressure melakukan pemblokiran impuls nyeri yang akan di transmisikan ke otak lebih cepat dibandingkan dengan cara kerja abdominal lifting.

Hasil penelitian ini sependapat dengan hasil penelitian yang dilakukan oleh Sri, Ulfa, dan Retno yang memberikan hasil bahwa teknik counter pressure lebih efektif terhadap penurunan nyeri pada persalinan normal. Juga penelitian yang dilakukan oleh Rina, Asiandi, Rohmi menunujukkan bahwa tehnik couter pressure efektif untuk menurunkan intensitas nyeri persalinan normal.

Menurut asumsi peneliti, walaupun nyeri persalinan adalah hal fisiologis yang dapat membuat ibu takut menghadapi persalinan, jika kondisi tersebut bias ditanggulangi dengan membawa klien memasuki kondisi relaksasi dan melakukan penekanan sacrum secara bergantian dengan tangan yang dikepalkan secara mantap dan beraturan, untuk mempertahankan kondisi relaksasi tersebut, sehingga mengurangi rasa nyeri yang dialami responden. Teknik ini tidak hanya dapat dilakukan oleh bidan tetapi juga dapat dilakukan oleh keluarga terutama suami karena keberadaan suami disaat ibu melahirkan merupakan faktor penting sebagai bentuk dukungan psikologis bagi ibu. Selain melakukan massage counter pressure suami dapat membantu ibu relaks dengan mengajak berceriita dan memenuhi kebutuhan nutrisi hidrasi ibu.

Tabel 4 Efektifitas Teknik Abdominal Lifting Terhadap Skor Nyeri Persalinan Kala I Fase Aktif

\begin{tabular}{|c|c|c|c|c|c|c|}
\hline $\begin{array}{c}\text { Skor } \\
\text { Nyeri }\end{array}$ & n & Mean & SD & Min & Max & $\underset{\text { Value }}{\mathbf{p}}$ \\
\hline $\begin{array}{l}\text { Sebelum } \\
\text { dan } \\
\text { Sesudah } \\
\text { Teknik } \\
\text { Abdominal } \\
\text { Lifting }\end{array}$ & 16 & 0.44 & 1.03 & $\begin{array}{c}- \\
0.11\end{array}$ & 0.98 & 0.110 \\
\hline
\end{tabular}

Berdasarkan tabel 4, dari 16 orang responden didapatkan perbedaan rata-rata skor nyeri persalinan kala I fase aktif sebelum dan setelah dilakukan teknik abdominal lifting yaitu 0,44 dengan standar devisiasi 1,03. Hasil uji statistik dengan menggunakan paired sample t-test didapatkan nilai $\mathrm{p}$ value : 0.110 , artinya Ho diterima dan tidak terdapat perbedaan skor 
nyeri persalinan kala I fase aktif sebelum dan setelah diberikan teknik Abdominal Lifting pada ibu bersalin di BPM Kota Padang.

Teknik abdominal lifting dilakukan dengan cara memberikan usapan berlawanan ke arah puncak perut tanpa menekan ke arah. Hal tersebut dapat merangsang serat saraf besar meningkatkan mekanisme aktivitas substansia gelatinosa yang mengakibatkan tertutupnya pintu mekanisme sehingga aktivitas sel $\mathrm{T}$ terhambat dan menyebabkan hantaran rangsangan ikut terhambat dan nyeri tidak akan dihantar ke korteks serebri. Proses tersebut lebih lambat daripada pemblokiran impuls nyeri ketika dilakukan teknik counter pressure.

Menurut Erickson Setelah dilakukan pijat abdominal lifting skor intensitas nyeri semua responden menurun, meskipun ada yang tidak dratis penurunannya. Ibu yang mendapat pijatan selama dua puluh menit setiap jam selama konraksi dalam persalinan akan lebih terbebas dari rasa sakit. Hal ini disebabkan karena pijatan merangsang tubuh untuk melepaskan endorphin yang berfungsi sebagai pereda rasa sakit dan menciptakan perasaan nyaman. Pijatan secara lembut ini membantu ibu merasa lebih segar, rileks, dan nyaman dalam persalinan.
Menurut peneliti, kerjasama yang baik antara bidan dan responden memiliki pengaruh besar terhadap keberhasilan proses teknik abdominal lifting. Proses membangun rasa saling percaya antara bidan dan responden dilakukan pada fase pre induksi. Keberhasilan tahap kedua yaitu induksi, sangat ditentukan oleh pre induksi, jika bidan tidak bisa membawa responden dalam posisi nyaman dan tenang, maka efek dari pijat menjadi tidak optimal. Pada penelitian ini, proses pengurangan skor nyeri yang tidak begitu signifikan dapat disebabkan oleh responden yang tidak bisa diajak kerjasama dikarenakan nyeri dan rasa cemas yang dirasakan semakin meningkat sehingga mempengaruhi perhatian ibu untuk dilaksanakan abdominal lifting.

\section{SIMPULAN}

Rata-rata skor nyeri persalinan kala I fase aktif sebelum dilakukan teknik counter pressure dan abdominal lifting berada pada kategori sangat berat yaitu 7,81 dan 7,63. Rata-rata skor nyeri persalinan kala I fase aktif setelah dilakukan teknik counter pressure dan abdominal lifting berada pada kategori berat yaitu 6,56 dan 7,19. Terdapat efektifitas teknik counter pressure terhadap pengurangan skor nyeri persalinan kala I fase aktif dengan nilai $p: 0,000$. Tidak terdapat efektifitas teknik abdominal lifting 
terhadap pengurangan nyeri persalinan kala I fase aktif dengan nilai $\mathrm{p}: 0,110$.

\section{DAFTAR RUJUKAN}

Bobak, dkk. (2005). Buku Ajar Keperawatan Maternitas. Edisi 4. Jakarta: EGC

Danuatmaja, B., Meiliasari, M. (2004).Persalinan Normal Tanpa Rasa Sakit. Jakarta

Hidayat, A. Aziz, Alimul. (2006). Pengantar Kebutuhan Dasar Manusia: Aplikas Konsep dan Proses Keperawatan. Jakarta: Salemba Medika.

Karami, Khoda. (2008). Effect of Massage Therapy on Severity of Pain and Outcome of Labor in Primipara.

Mander,R. (2003). Nyeri Persalinan. Jakarta: EGC.

Maryunani, Anik (2010). Nyeri dalam Persalinan "Teknik dan Cara Penangananya”. Jakarta: Trans Info Media

Monsdragon. (2004) Pregnancy Information (Effleurage and massage)

Mulati, T. S., Handayani S.R., \& Arifin, Z. (2007). Perbedaan Antara Pengontrolan Nyeri Pinggang Persalinan dengan Teknik Superficial Heat-Cold dan Teknik Counterpressure Terhadap Efektifitas Pengurangan Nyeri Pinggang Pada Kala I Persalinan Studi di Rb Wilayah Klaten.

Murray, M. L., \& Huelsman, C. M. (2009). Labor and Delivery Nursing: A Guide To Evidence Based Practice. New York: Springer

Nastiti Raras. (2012). Perbedaan Efektifitas Teknik Back-Effelurage dan Teknik Counter Pressure Terhadap Tingkat Nyeri Pinggang Kala I Fase Aktif

Notoatmojo, Soekidjo (2010). Metodologi Penelitian Kesehatan. Jakarta: Rineka Cipta.
Phumdoung S, \& Rattanaparikonn A. (2003). Factors related to labor pain. Obstetri Gynecological Nursing and Midwifery Department, Prince of Songkla

University, Hat Yai, Songkhla, 90110. Thailand. Diakses 20 Agustus 2013

Reeder, Martin, Koniak-Griffin.(2012). Keperawatan Maternitas : Kesehatan Wanita, Bayi dan Keluarga. Alih bahasa Yati Afiyati, dkk. Edisi 18. Jakarta : EGC

Simkin P \& Ancheta R. (2005). Buku Saku Persalinan. Jakarta : EGC

Thompson T .(2008). Anxiety Sensitivity And Pain: Generalisability Across Noxious Stimuli. Diakses 25 April 2013

Widjaja, Harjadi. (2010). Anatomi Panggul. Jakarta : EGC Winkjosastro. (2002).

Prawirohardjo, Sarwono. Ilmu Kebidanan Edisi Ketiga. Jakarta: Yayasan Pustaka Sarwono Prawiroharjo

Pasongly Seri, dkk. (2014). Efektivitas Couterpressure terhadap Penurunan Intensitas Nyeri Kala I Fase Aktif Persalinan Normal di Rumah Sakit Advent Manado. Manado. Jurnal Ilmiah Bidan Volume 2 Nomor 2. Juli - Desember 2014 ISSN : 23391731 [12 Oktober 2018]

Monsdragon. Pregnancy Information (Effleurage dan massage). (2004) [13 Oktober 2018.]; diakses dari http://www.monsdragon.org/pregnan cy

Pratiwi D A, Heni Setyowati, $d k k$. Efektifitas Tehnik Abdominal dan Counter pressure Dalam Menangani Nyeri Persalinan Fase Aktif Kala I di RSUD Tidar Magelang. Magelang: Program Studi Ilmu Keperawatan Universitas Muhammadiyah (2013) [13 Oktober 2018]; diakses dari http://.jurnal.ummgl.ac.id/ 
Winkjosastro. (2002). Ilmu kebidanan edisi ketiga. Jakarta: Yayasan Pustaka Sarwono Prawiroharjo

Wirakhmi Ikit Netra (2013). Pengaruh Counter Pressure Terhadap Intensitas Nyeri Kala I Pada Ibu Bersalin Didapatkan Skala Nyeri Persalinan Kala I di Wilayah Kerja Puskesmas Pekuncen. Viva Medika Volume 07/Nomor 12/Februari/2014. [13 Oktober 2018.]

Sri Rejeki, Ulfa Nurullita, dkk. Tingkat Nyeri Pinggang Kala I Persalinan Melalui Teknik Back- Effluerage dan Counter Pressure. Jurnal Keperawatan Maternitas. Volume 1, No. 2 pp. 124-33.[ 13 Oktober 2018]

Rina Sri Hastami, Asiandi, dkk. Efektifitas Tehnik Kneading dan Counterpressure Terhadap
Penurunan Intensitas Nyeri Kala I fase Aktif Persalinan Normal di RSIA Bunda Arif Purwokerto Tahun 2011. Purwokerto: Program Studi Fakultas Kesehatan Universitas Muhammadiyah (2011) [13 Oktober 2014]; diakses dari http://.akbidylpp.ac.id.

Yeltra Armi, dkk. (2014). Efektifitas Pijat Abdominal Litfing Terhadap Pengurangan Rasa Nyeri Persalinan Pada Ibu Primigravida dalam Persalinan Kala I di Bidan Praktek Mandiri Bd Y Lubuk Alung Tahun 2014. Jurnal Kesehatan STIKes Prima Nusantara Bukittinggi, Vol.5 No 1 Januari 2014. [13 Oktober 2018]; diakses dari download.portalgaruda.org 